\section{THE JOYS OF COLLECTING} MATMEMATICAL BOOKS

\section{Rod Gow}

I would like to describe an engrossing hobby that I took up about two years ago, namely, the collecting of mathematical books of some antiquity or historical value. This activity has proved to be an impetus for discovering more about the historical development of mathematics, both at the research and teaching level. I hope that readers will find some aspects of the economics and mechanics of collecting specialized books to be of interest.

$\mathrm{My}$ introduction to the world of antiquarian books dates from the death in 1990 of my father-in-law Con Gillman, who was a graduate in physics of UCC and possessor of an M.Sc. in statistics. He left a large number of books in the study and attic of his house. These books posed a problem of dispersal, as they occupied much space and would eventually have to be moved. Examination of these books revealed titles in philosophy, poetry, mathematics, statistics, physics, meteorology and engineering. While I was not particularly enthusiastic about many of the books, I was impressed by a group of physical and mathematical books that had probably been collected in the 1930's or 40's. These included works by such authors as Rutherford, J. J. Thomson, Dirac, Fermi, W. Thomson (Lord Kelvin) with whom I was more or less familiar. Other authors included W. Stanley Jevons, John H. Pratt, Isaac Todhunter and Joseph Wolstenholme, names which then meant nothing to me. My attempts to find out more about these authors and their work have led me into the fascinating world of the history of science and scientific literature and ultimately to that of book collecting.

An obvious source for enquiring about British and Irish scientists or academics of earlier times is the Dictionary of National
Biography or DNB. The DNB has sometimes provided the only information I have been able to find on authors whose work I have encountered. For instance, I read that Wolstenholme (182991) was a clergyman, a fellow of Christ's College, Cambridge and professor of mathematics at the Royal Indian Engineering College in London. He is best known for his Mathematical Problems, published in three editions (1867, 1878 and 1891) by Macmillan and Co. He apparently did much work as an examiner for the mathematical tripos in Cambridge and as a consequence built up a large store of problems, which formed the basis of his book. The 1878 version has 2815 problems, occupying 480 pages. Unfortunately, most of these problems seem to be unsuitable for present day students (there are 936 problems on conic sections but only 26 on probability). Another useful source of information is the Encyclopedia Britannica. The earlier editions of Britannica often had detailed biographical and expository articles, which were subsequently edited and shortened in later editions, thereby losing much of their charm. Copies of various editions (but not the most recent or earliest ones) of Britannica can often be bought at auction or from dealers for around $£ 100-150$ and are a great asset to the bibliophile or amateur of scientific history.

A more detailed source is the Dictionary of Scientific Biography or DSB, edited by C. Gillispie and published (1970-76) by Charles Scribner's Sons. This consists of 14 volumes, together with two supplements, and contains biographical articles on people connected with science and mathematics from Greek times up to the present century. Many of these articles are full and authoritative, being written by named experts in the relevant field, although occasionally, some seem rather short and disappointing. Many of the minor scientists, about whose work or books I may wish to have more detail, probably have not merited attention in the DSB, although they often feature in the DNB. While a personal copy of the DSB would be invaluable to any enthusiast of the history of science, second-hand sets are not so easily obtained and would probably cost at least $£ 700$. More recently (1991), the articles from the DSB relating to mathematicians have been published in four separate volumes. 
Having found information about the authors of the books I had acquired, I then wondered if any of the books was at all rare or valuable. The novice, when confronted by antiquarian books, will usually have little idea of what might be a reasonable price to pay for any particular item. In some respects, this will always remain a problem, as prices can fluctuate wildly, depending on who is selling. One may come across bargains, where the seller has little idea of the value attached to an item by an enthusiast. Equally, absurdly high prices may be demanded by dealers who have bought relatively cheaply and intend to sell on expensively. The problems of buying and selling in a very small market are delicate and probably do not conform to the more normal economics of production and retail of essential commodities.

There are various ways to obtain some picture of how much antiquarian or rare books cost. One is to visit as many secondhand book shops as possible and see what prices are demanded for particular items. However, if your interest is in scientific literature, there will not be many such shops that have more than a. few isolated examples to examine. In Dublin, there are several second-hand and antiquarian book shops and dealers, but most specialize, not surprisingly, in Irish literature, history, topography and travel. Nonetheless, occasionally something of scientific merit may creep in and a certain amount of sustained but generally fruitless searching will locate a worthwhile item. Another possibility is to find the names of specialized dealers who conduct their business by mail and write to them for catalogues. I have made use of two such dealers, who advertise their facilities in mathematical magazines. Their catalogues are very instructive and provide quick access to information about prices and rarity. I noted a copy of Hamilton's Lectures on Quaternions of 1853 on sale in one catalogue at $£ 180$, which struck me as reasonable value (doubtless it was sold almost instantly). Often, dealers whose speciality is not in science may have one or two scientific items and I will usually try to browse through any catalogue that comes my way. It is clear that any pre-19th century mathematical or scientific book is likely to cost at least $£ 30$ if it is not badly damaged and often more than $£ 100$ if the author is famous or the condition is good.

Pre-18th century scientific books are now very uncommon and Pre-18th century scient, except from top-class dealers, who often charge top-class prices. On the whole, for the purchaser of limited means, pre-18th century scientific material is largely out of the question.

Instead of buying through a dealer, one may decide to try buying at auction. In London, Christies and Bloomsbury Book Auctions, among others, have annual auctions of scientific books. I have never attended any such auction, but many dealers obtain their stock by buying at these specialized auctions. A valuable guide in this respect is Book Auction Records or BAR, published by Dawson, which has appeared annually for many decades. The BAR provides information on sales in auction houses throughout the world, the condition for inclusion of any sale being that the item sold must have fetched at least $£ 70$. I enjoy browsing through the copies of BAR and have noticed various sales of mathematical note. For example, a copy of Boole's An Investigation of the Laws of Thought sold in 1991 for $£ 3,900$ at an auction conducted by Dominic Winter's of Swindon. This copy once belonged to W. S. Jevons and had a letter of 1868 from Augustus de Morgan to Jevons tipped into it. Boole's book was published by Macmillan and Co. in 1854 and was still described in Macmillan's 1879 catalogue as available for $14 \mathrm{~s}$. While the price paid above was obviously enhanced by the association with Jevons, any copy is likely to cost hundreds of pounds nowadays. It is sometimes possible to identify an item bought at auction with a similar item in a dealer's catalogue and thus deduce the dealer's mark up. One must expect a mark up of at least $50 \%$ but one of $200 \%$ or $300 \%$ is not unknown.

In Ireland, the main book auctions are those conducted by Mealy's of Castlecomer. These occur twice or more a year, in the Montrose Hotel in Dublin or in Castlecomer. Mealy's auctions usually have one or two lots of mathematical intertst but they cater more for the Irish literary and historical tastes that I described above. In December 1991, before the start of my interest, Mealy's Dublin sale had three mathematical lots: a first edition of Thomas Simpson's Treatise of Algebra of 1745 (the 
Simpson of Simpson's rule), a second edition of Robert Simson's Sectionum Conicarum Libri $V$ of 1750 (Simson was professor of mathematics in Glasgow and the editor of a version of Euclid that was much followed and imitated for many years) and a third edition of Newton's Principia of 1726. Copies of the 1726 Principio are not nearly as rare as those of the first edition of 1687 . Perusal of the BAR suggests that $£ 400-1000$ might be the price to pay for the 1726 Principia, depending on condition, historical associations and so on. I wonder who bought the three books above and what they paid.

I have related how my interest in antiquarian scientific and mathematical books was awakened and how I tried to learn more about their history and prices. Enthused by this initial impetus, I decided in 1992 that, using my father-in-law's books as a nucleus, I would try to extend his collection, specializing in mathematical work, with a subsidiary interest in other scientific subjects. So, collecting mathematical books has become a new hobby. There are probably not many people in Ireland with similar interests in mathematical books, so that competition in the market is smal but, on the reverse side, there are not many outlets for the material I seek. I might add that, as far as I can see from my investigations, the most valuable of my father-in-law's books is probably Histoire des mathématiques by Jean Montucla (1725-99). This consists of two quarto volumes published in Paris in 1758. It is considered to be one of the best early histories of mathematics.

Let me describe some of the books that I have acquired There is a copy of the second issue of Legendre's Elements of Geometry of 1824 , edited by David Brewster. (Virtually no copies of the first issue of 1822 are known.) This is an English translation of the eleventh edition of Legendre's French original, which firs appeared in 1794. The translation was made by Thomas Carlyle who is better known as an essayist and historian. Carlyle included an introduction 'On Proportion', written by himself. He was paid $£ 50$ for the translation. According to an article by J. H. Webb in the Mathematical Gazette for June 1974, Carlyle eventually tired of the translating work and persuaded his brother to take over. In Legendre's French text there is a definition of a straight line by 'La' ligne droite est le plus court chemin d'un point à un autre'. This was mistranslated by Carlyle as 'A straight line is the shortest distance from one point to another' (the mistranslation occurring in the word 'chemin', which means 'path' rather than 'distance').

I was particularly pleased to buy $A$ History of the Mathematical Theory of Probability from the Time of Pascal to that of Laplace by Isaac Todhunter, published in 1865 by Macmillan and sold at a price of $18 \mathrm{~s}$. Even today, historians of probability and statistics refer to Todhunter's text for its detailed description of the development of the first 150 years of the theory. The work is described as very scarce in the catalogue Bibliothece ChemicoMathematica of 1921 and copies of it were offered for sale at $£ 2$ 2 s, $227 \mathrm{~s} 6$ d and $£ 215$ s. Another classical text that 1 obtained on probability theory is Choice and Chance by W. A. Whitworth. This appeared in fve editions between 1867 and 1901 . The edition I bought was the fourth, published in 1886 . It contains 640 exercises on elementary probability theory and combinatorics and is still useful to anyone who has to devise problems for a finite mathematics course. Incidentally, Whitworth was vicar of All Saints', Margaret Street, London, a well-known centre of High Church Anglicanism.

I mentioned the Bibliotheca Chemico-Mathematica above and I will take the opportunity to describe the virtues of this publication. It is an historical catalogue of scientific books that were available for sale at Henry Sotheran and Co. of London. (Sotheran's is still one of the major dealers in antiquarian books in London.) The work is quite extensive and a valuable source for those wishing to research scientific literature. It is now a collector's item and well worth owning by the enthusiast. A look at prices is instructive: A first edition of Prineipia-was available for 18 guineas and was described as excessively scarce. The going rate at auction for such a first edition seems to be $£ 20,000-30,000$ for a good copy nowadays. It is not known exactly how many copies of the first edition of Principia were printed, although estimates of between 250 and 400 copies have been made. Leather bound copies of the book retailed for $9 \mathrm{~s}$ initially but apparently the book had become scarce very quickly and people were paying much 
more for second-hand copies. In 1691 , it is recorded that a copy was bought for about 2 guineas. It should be borne in mind that a good husbandman could be hired for between $£ 3$ and $£ 4$ a year (information from the Mathematical Gazette for December 1948).

Many of the books in Bibliotheca Chemico-Mathematica now cost between 500 and 1000 times what they cost 70 years ago. This is particularly true of books whose authors have become famous (like Babbage or Boole) or books produced in small print runs. (A sum invested at $10 \%$ interest compounded annually would increase 1000 fold in about 72 years.) On the other hand, some text books have really declined in value over the years when inflation is taken into account. For example, the first edition of Todhunter's Analytical Statics was published by Macmillan in 1853 and sold at $10 \mathrm{~s}$ $6 \mathrm{~d}$, which seems expensive for the time. The fifth edition of the book was still on sale in 1890 at the same price. Today, this book would probably cost no more than $£ 15$, so that it has not held its value over 140 years. Boole's Laws of Thought was available from Sotheran's for $£ 115 \mathrm{~s}$ and it was described as very scarce. Group theorists who know the impact made in the last century by Camille Jordan's Traité des substitutions, published in 1870, may like to know that this work was available from Sotheran's for $£ 3$ $7 \mathrm{~s} 6 \mathrm{~d}$ and described as very scarce. I have not heard of an original copy for sale in recent times.

In conclusion, I would like to make a small advertisement. I am interested in buying books, papers or magazines of a scientific or mathematical nature, preferably pre -20 th century. If you have any such items that you wish to dispose of, you may think of contacting me at the address below.

Department of Mathematics

University College

Belfield

Dublin 4

email: rodgow@irleam.ucd.ie

\section{POLYNOMIALS AND STRIDS}

\section{IN BANACII SPACES*}

\section{Manuel González ${ }^{\dagger}$ and Joaquín M. Gutiérrez ${ }^{\dagger}$}

Abstract: We show that homogeneous polynomials acting on Banach spaces preserve weakly unconditionally Cauchy (w.u.C.) series and unconditionally converging (u.c.) series. This fact allows to define the class of unconditionally converging polynomials as those taking w.a.C. series into u.c. series. It includes most of the classes of polynomials previously considered in the literature. Then we study several "poly. nomial properties" of Banach spaces, defined by relations of inclusion between classes of polynomials. In our main result we show that a Banach space $E$ has the polynomial property (V) if and only if for all $k \in \mathbb{N}$ the space of homogeneous scalar polynomials $\mathcal{P}\left({ }^{k} E\right)$ is reflexive; hence, its dual space $E^{*}$, like the dual of Tsirelson's space, is refiexive and contains no copies of $\ell_{p}$

Throughout the paper, $E$ and $F$ will be real or complex Banach spaces, $B_{E}$ the unit ball of $E$ and $E^{*}$ its dual space. We will write $\mathbf{K}$ for the scalar field, which will be always $\mathbf{R}$ or $\mathbf{C}$, the real or the complex field, and $\mathrm{N}$ for the natural numbers. Moreover, $\mathcal{P}(E, F)$ will stand for the space of all (continuous) polynomials from $E$ into $F$. Any polynomial $P \in \mathcal{P}(E, F)$ can be written as a sum of homogeneous polynomials: $P=\sum_{k=0}^{n} P_{k}$, with $P_{k} \in \mathcal{P}\left({ }^{k} E, F\right)$, the space of all $k$-homogeneous polynomials from $E$ into $F$.

*This note is a summary of the talk given by the second author at the 5th September Meeting of the Irish Mathematical Society held in Waterford (1992)

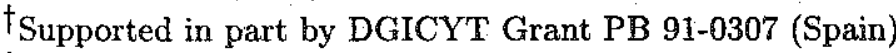

${ }^{\ddagger}$ Supported in part by DGICYT Grant PB 90-0044 (Spain) 